\title{
Design of a Pulse Power Supply Unit for Micro ECM
}

\author{
Alexandre SPIESER, Atanas IVANOV
}

Brunel University

School of Engineering \& Design, Advanced Manufacturing and Enterprise Engineering

\begin{abstract}
Electrochemical micromachining $(\mu \mathrm{ECM})$ requires a particular pulse power supply unit (PSU) to be developed in order to achieve desired machining performance.

This paper summarizes the development of a pulse PSU meeting the requirements of $\mu \mathrm{ECM}$. The pulse power supply provides tens of nanosecond pulse duration, positive and negative bias voltages, and a polarity switching functionality. It fulfils the needs for tool preparation with reversed pulsed $\mathrm{ECM}$ on the machine. Moreover, the PSU is equipped with an ultrafast over current protection which prevents the toolelectrode from being damaged in case of short-circuits.
\end{abstract}

The developed pulse PSU was used to fabricate micro tools out of $170 \mu \mathrm{m}$ WC-Co alloy shafts via micro electrochemical turning and drill deep holes via $\mu \mathrm{ECM}$ in a disk made of $18 \mathrm{NiCr} 6$. The electrolyte used for both processes was a mixture of sulphuric acid and $\mathrm{NaNO} 3$ aqueous solutions.

Keywords - Micro ECM, micromanufacturing, pulse PSU, ultrashort pulses, Tungsten carbide alloy, micro tool

\section{INTRODUCTION}

Electrochemical micromachining $(\mu \mathrm{ECM})$ is a nonconventional manufacturing process based on the process of electrolysis: The anode (workpiece) and the cathode (toolelectrode) are both submerged in a constantly renewed electrolytic solution and a high frequency pulsed voltage is applied (Figure 1). Anodic dissolution occurs, material is removed and the workpiece is shaped according to the features of the tool-electrode [1].

$\mu E C M$ enables the precise machining of micro-features by using the capacitive properties of the electrical double layer (EDL) which forms itself along the surfaces of the electrodes. The dissolution process can be accurately confined by setting the pulse duration according to the charging time of the EDL [2-6]. The frequency and the pulse duration are respectively higher and shorter than in initial PECM [7, 8]. This process requires a pulse power supply unit (PSU) that is able to deliver pulses at very high frequency with an adjustable pulse duration. The amount of information in the literature on the development of a pulse PSU for $\mu \mathrm{ECM}$ is very limited. Most of the published research uses 'off-the-shelf' signal generators which are not designed for electrochemical machining (low output power, slow short circuit protection and no interface available for the control system) and are very costly. A low cost power supply unit with satisfying performance will have to be developed in order to make the $\mu \mathrm{ECM}$ technology fulfil the needs of the industry [9]. Further research is therefore needed in this particular area.

\section{DESIGN CONSIDERATIONS AND REVIEWS}

\subsection{ON-THE-MACHINE TOOL ETCHING}

In $\mu \mathrm{ECM}$ drilling and milling operations, the tool-electrode can be fabricated online by electrochemical etching [4, 10-14] or in a manner similar to the Wire Electro-Discharge Grinding devices which allows to achieve very small sizes $[15,16]$.

Figure 2 shows an example of a micro tool electrode being machined using electrochemical etching (with a DC voltage) followed by the machining of the workpiece (with a pulsed voltage).

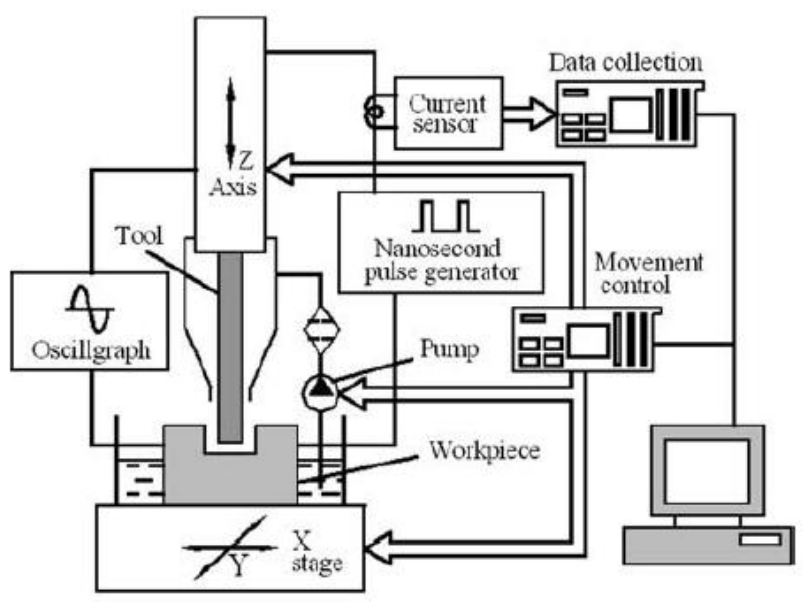

Figure 1. Schematic diagram of a $\mu$ ECM system [4] A MICRO-MACHINING SYSTEM
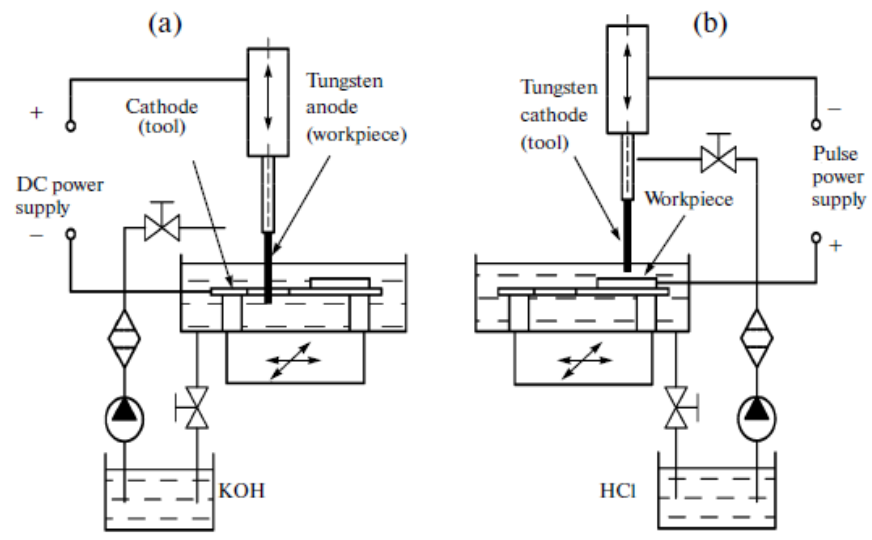

Figure 2. Schematic diagram of micro-ECM sequentially: (a) micro tool machining, (b) micro-workpiece machining [10]

One of the major benefits of the on-the-machine electrode preparation is that the axis of rotation of the spindle and the tool-electrode become the same (eliminating run-out errors).

A single pulse PSU able to reverse polarity to machine both the tool and the workpiece would therefore be very 
convenient. This is therefore one of the requirements that the developed pulse PSU should fulfil.

\subsection{ELECTRICAL CONNECTIONS}

Burkert et al. stated that one of the critical parameters of the $\mu E C M$ process circuitry is the parasitic inductance of the cables connecting the PSU to the electrodes. Special low inductance cables should be used and their length must be minimised when high frequency pulse trains are applied to the IEG [17, 18]. Therefore the PSU has to 'be positioned as close as possible' to the IEG [17]. The use of coaxial cables to minimise cable inductance has also been reported [19].

It is known that spinning the tool during $\mu \mathrm{ECM}$ results in an improved renewal of electrolyte, more uniform shaping and fewer short circuits. The electrical connection of the rotating electrode is complex to achieve because the high frequency signal must be reliably transmitted to the rotating element [20]. The authors propose two solutions: 1) to have the transmission of the power through a liquid metal bath (e.g. mercury or galinstan) by designing a slip ring. 2) to use a ring with microfiber carbon brushes, usually used in shaft grounding applications [21].

The PSU should be very easy to mount and occupy a limited amount of space. The pulse PSU will be installed on the 3 axis machine so the cabling shall be carefully designed to avoid restricting the motion.

\subsection{POWER SUPPLY UNIT DESIGN REVIEWS}

In $\mu$ ECM the PSU should be able to apply pulses with the following characteristics:

- Pulse amplitude: 1-10V [22]

- Current: up to 5A (depending on the cathode working area)

- Frequency: ranging from $2 \mathrm{kHz}$ up to $8 \mathrm{MHz}$ with a minimum pulse duration of 50ns.

This kind of device is difficult to design mainly because it requires its power components (e.g. MOSFETs) to be switched at a very high frequency. Most of the silicon-based power transistors commercially available are designed to work at a maximum switching frequency of $1 \mathrm{MHz}$ and are limited by their turn-on and turn-off times. To make a MOSFET turn on in a few nanoseconds, a high current pulse (of several amperes) has to be applied to quickly charge the capacitor at its gate [23, 24]. For this reason a special gate driver needs to be developed in most cases [25].

Although the design of single-switch pulse generators has been reported (use of a RF MOSFET [26] and use of a thyristor [22]), most of the $\mu \mathrm{ECM}$ power supplies found in the literature have a half bridge (push-pull) configuration [17, 20, 27]. Driving the high side switch at a very high frequency is also problematic, since the conventional high side gate drive technique using a bootstrap diode and a bootstrap capacitor cannot be used (because of the relatively long charging/discharging time of the bootstrap capacitor). A solution to this problem is to completely isolate the high side using an isolated DC/DC converter.
Machining at a very small interelectrode gap dramatically increases the chances of short circuits to occur. Short circuits are very undesirable as they might damage the tool, alter the quality of the workpiece surface and even damage the pulse generator. Therefore, an ultra fast short circuit protection is necessary to be built into the power supply unit. Most of the solutions implemented for that purpose, measure the current flowing through the system via a sensing resistor in series with the gap. Moreover, the measured current can be used to control the IEG [7, 22, 28-31].

Zhang et al. proposed a power supply design and claimed they could achieve a pulse frequency of $20 \mathrm{MHz}$ using a MAX038 function generator to control the MOSFETs (Figure 3). They also presented a fast short circuit protection measuring the current through a sensing resistor [20].

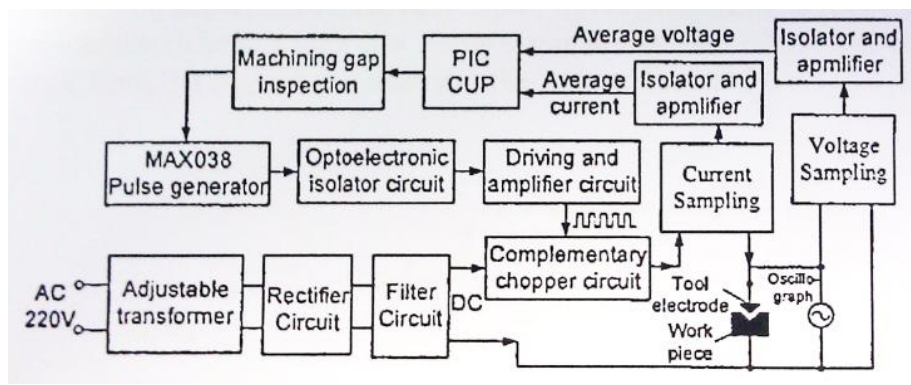

Figure 3. Schematic of pulse generator for micro-ECM [20]

Burkert et al. outlined the differences between the power supply units (PSU) in PECM and $\mu E C M$ [17]. In order to improve the localization of the machining, Burkert et al. claimed it is necessary to reload the double layer capacitance. They presented a bipolar PSU enabling to load/unload the electrical double layer thanks to two power sources, as shown on Figure 4.

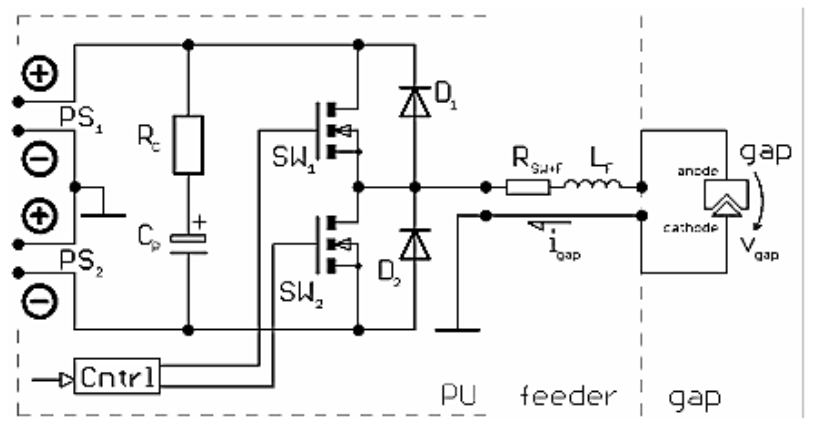

Figure 4. Basic circuitry of simple $\mu \mathrm{ECM}$ pulse-unit (PU) in push-pull topology with bipolar (two) power supply (PS) feeding. Switches SW may conduct in alternation for loading and reloading of the gap's double layer capacitance. [17]

\section{PROPOSED PULSE PSU DESIGN}

According the literature review, the possibility to reverse the polarity of the voltage and to set a positive/negative offset during the pulse interval (off-time) would respectively greatly enhance the flexibility of the machine for on-line tool machining [10] and prevent metal deposition [32]. 
Therefore, a new pulse PSU design is proposed to perform an online machining of the tool followed by workpiece machining without having to modify the cabling. The pulse PSU will communicate with a Delta Tau Power PMAC motion controller and a custom-made human machine interface (HMI) developed using NI CVI/LabWindows.

The proposed pulse power supply concept is presented on Figure 5 and will be able to quickly reverse the pulse polarity using an $\mathrm{H}$ bridge circuit configuration. The $\mathrm{H}$ bridge is composed of 4 N-type MOSFETs (SW1, SW2, SW3, and SW4):

When SW_pulse, SW1 and SW4 are turned on, a positive voltage is applied to the IEG and the workpiece is machined.

When SW_pulse, SW2 and SW3 are turned on, a negative voltage is applied to the IEG and the tool is machined.

It is therefore possible to apply a positive voltage during the pulse duration, followed by a negative voltage during the pulse interval (off-time).

SW1 and SW2 shall never be turned ON at the same time, as it would short circuit the power sources $\mathrm{V}_{\text {pulse }}$ and $\mathrm{V}_{\text {offset }}$.
The machining current is measured via a sensing resistor in series with the IEG. The voltage across this resistor is amplified and sent to both the overcurrent protection (for short circuit and tool protection) and the control system -via a peak detector- (for gap control purpose).

\subsection{THE CONTROL CIRCUITRY}

This power supply unit is controlled via an Arduino compatible Max32 ChipKIT development board having an $80 \mathrm{MHz} 32 \mathrm{bit}$ PIC microprocessor (from Microchip).

The Max32 development board is directly interfaced with the control circuitry of the pulse power supply unit. This control circuitry has been designed to be pin-to-pin compatible with the Max32 board so that it can be stacked on top of it. This modular design approach makes the development of the prototypes easier, since each of the boards can be tested and replaced individually without affecting the other working parts.

A pulse generator creates the logic signals that will control the MOSFETs on the power stage. It is made of a programmable oscillator LTC6904 connected to the trigger input of a programmable pulse generator 3D7622-0.25. The pulse generator will therefore output pulses at each rising edge of the signal coming from the LTC6904, thus creating a pulse train with adjustable frequency and duty cycle.

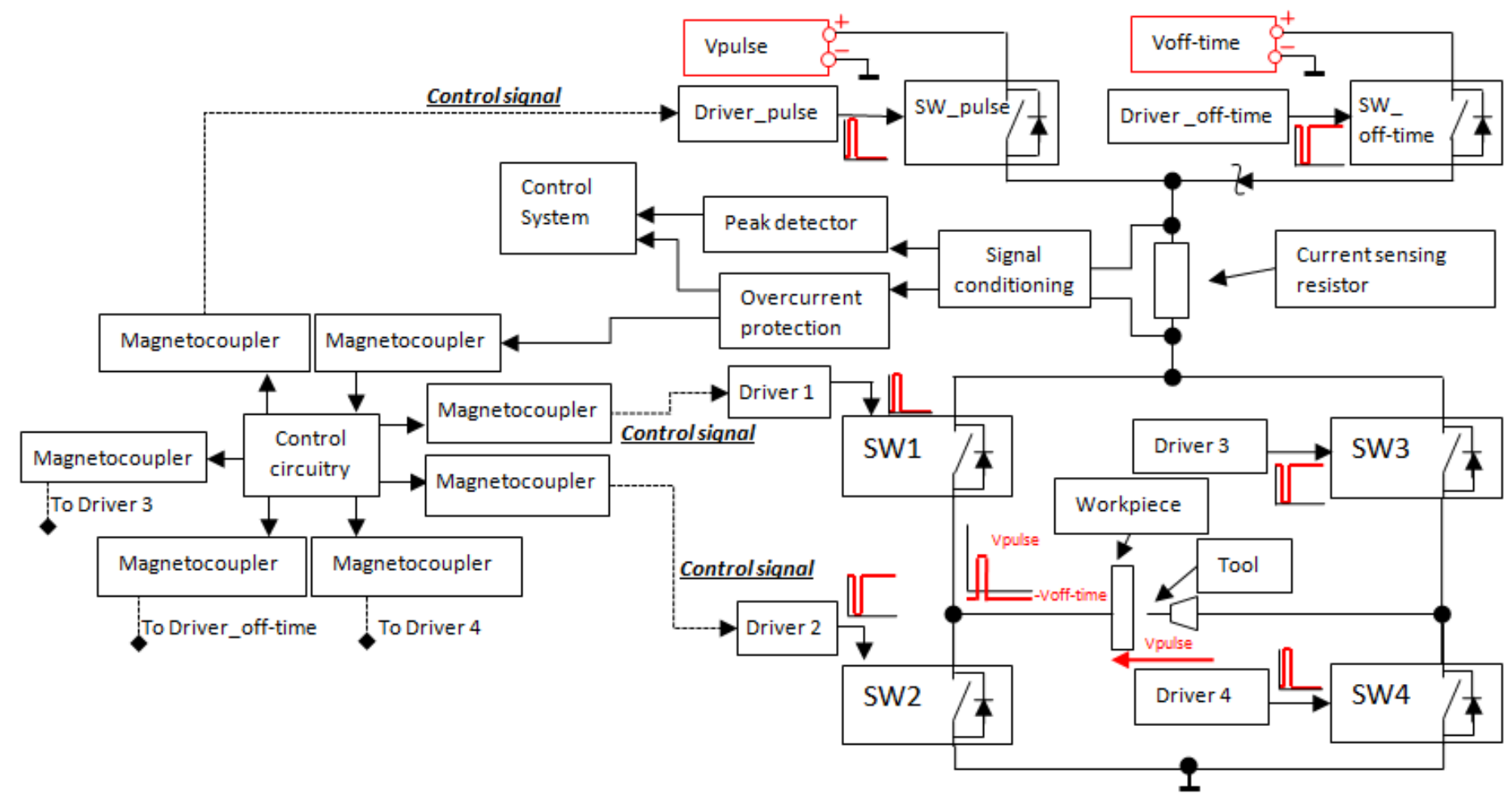

Figure 5. Schematic diagram of the second PSU prototype and its interfaces. The control system block designates the motion controller and the HMI. 


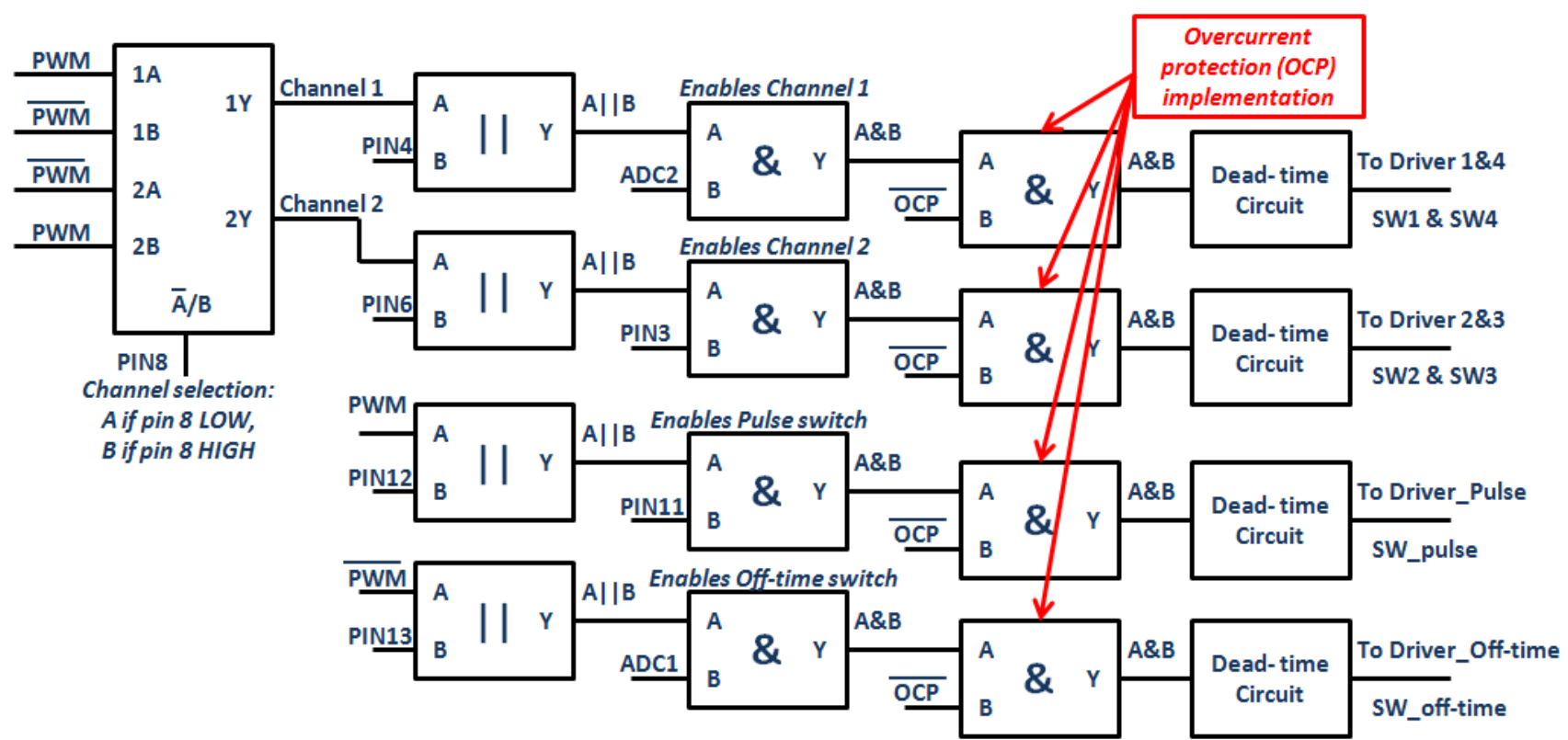

Figure 6. Schematic diagram of the control circuitry of the PSU prototype (the isolation has been removed from the schematic for simplification purposes)

The Max32 board communicates with the human machine interface, which sends all the data necessary to configure the pulse PSU: frequency, duty cycle, overcurrent protection threshold and desired pulse shape. Once the data is received, the microcontroller adjusts the frequency of the LTC6904 via I2C and sets the duty cycle thanks to the 3D7622-0.25 using the SPI communication protocol.

The control signals are connected to a multiplexer (74A157D) of which the outputs are connected to OR gates (74AC32D) used to maintain the MOSFET switches turned ON when necessary. Their output is then sent to other AND gates (74AC08D) but this time they are compared with the overcurrent protection (OCP) logic signal. If the OCP signal is
'High', it means that it has not been triggered and the signals at the outputs of the AND gates can be sent to the MOSFETs. If the overcurrent protection is triggered, the OCP signal goes 'Low' which stops sending of the control signal to the power stage and prevents the MOSFETs from being turned on when the output of the pulse power supply is short-circuited.

The dead time circuitry ensures there is no cross-conduction of the MOSFETs which would short circuit the output of the PSU.

Figure 7 shows the different combinations of switch states to obtain the desired pulse shapes.

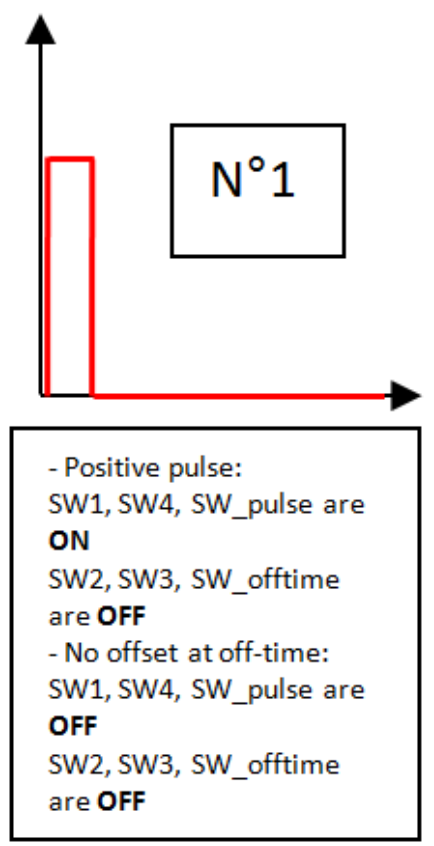

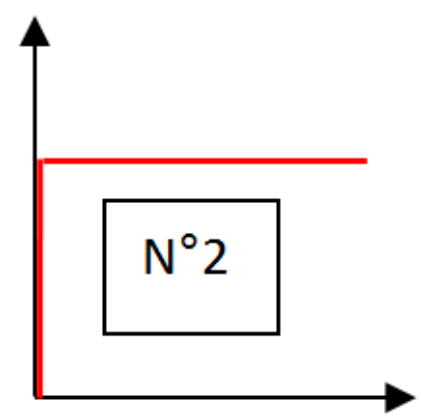

Positive DC voltage. No off-time.

SW pulse, SW1 and SW4 all forced $O N$ while SW2, SW3, SW_offtime are OFF

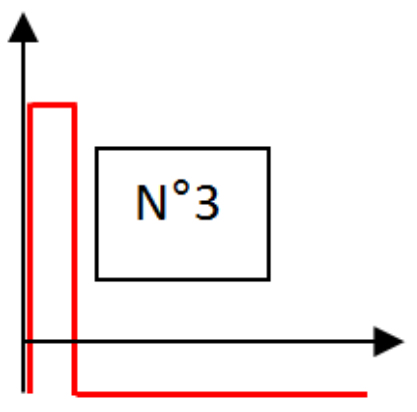
- Positive pulse:
SW1, SW4, SW_pulse are ON
SW2, SW3, SW_offtime are OFF
- Negative offset at off- time:
SW1, SW4, SW_offtime are $\mathbf{O N}$
SW2, SW3, SW_pulse are OFF

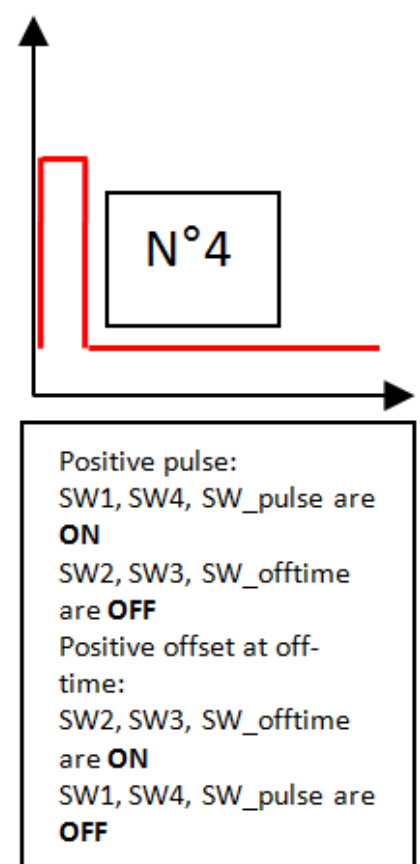



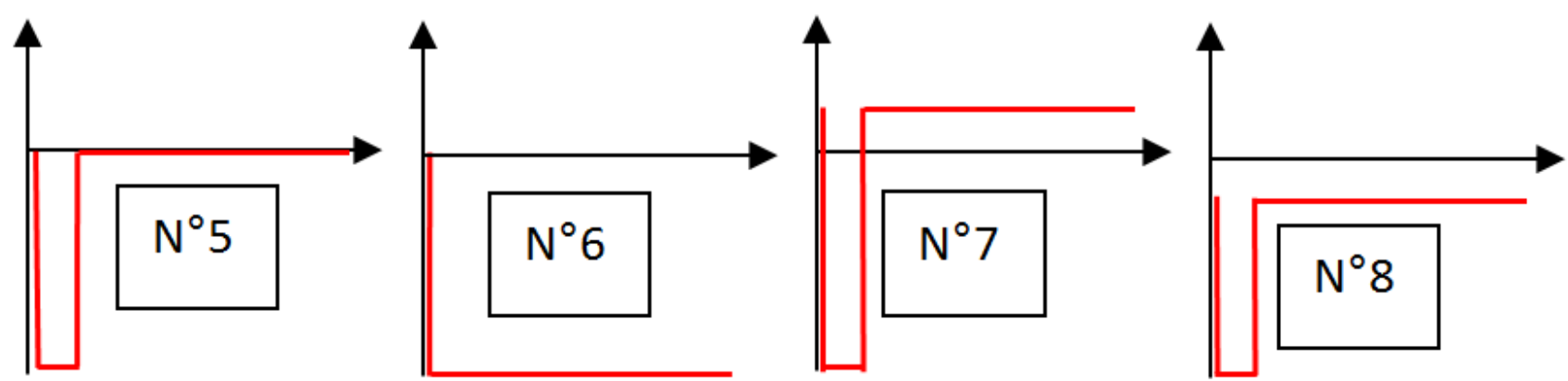

Negative pulse:

SW2, SW3, SW_pulse are ON

SW1, SW4, SW_offtime are $\mathbf{O F F}$

- No offset during pulse off-time:

SW1, SW4, SW_pulse are

OFF

SW2, SW3, SW_offtime

are OFF
Negative DC voltage.

No off-time.

SW pulse, SW2 and SW3

all forced $\mathrm{ON}$ while SW1,

SW4, SW_offtime are

OFF

Figure 7. Drawings representing the different pulse shapes that can be achieved with the proposed PSU design

\subsection{THE POWER STAGE}

The power stage contains the MOSFET that will turn on/off to create the voltage pulses. The developed prototype has been using conventional power MOSFETs and has a maximum switching frequency of $8 \mathrm{MHz}$ with a $5 \mathrm{~ns}$ rise time. These values have been measured with a Wavepro 7300A oscilloscope from Lecroy, featuring a sampling rate of 10GS/s in quad channel configuration and a $3 \mathrm{GHz}$ bandwidth.

The drivers of the switches SW_pulse and SW_offset, SW1 and SW3 are isolated from the ground thanks to 4 individual isolated DC-DC converters. This configuration allows driving the MOSFETs at a very wide range of frequencies and duty cycles.

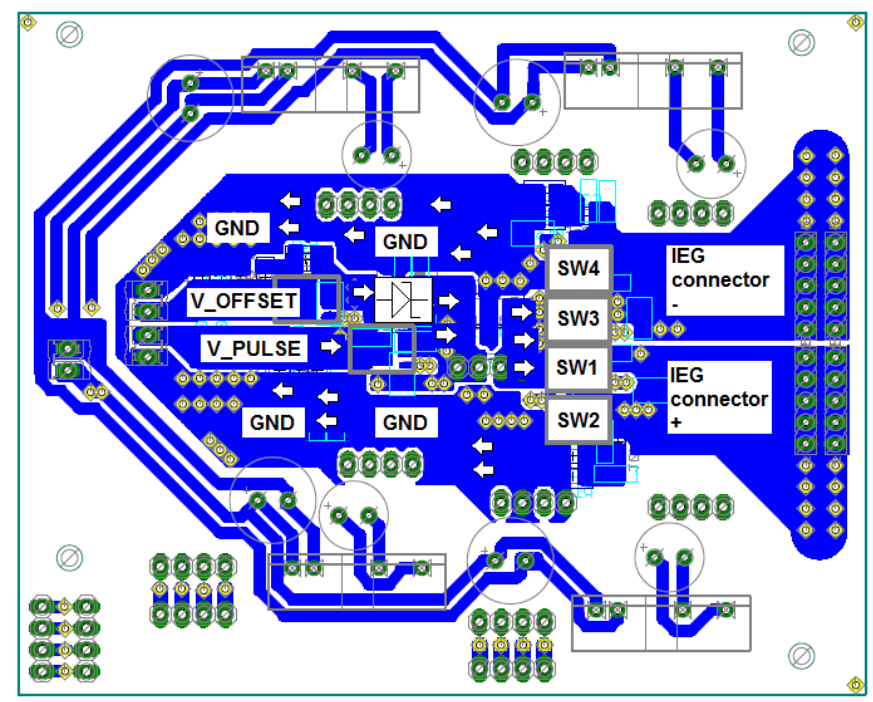

Figure 8. PSU prototype layout to optimise the current path and reduce overall inductance. Arrows symbolise the direction of the current.
A pin connector placed close to the current sensing resistors allows the current sensing circuitry board to be plugged onto the power stage board. The output of the current sensing circuitry board is interfaced with the control board in order to interrupt the pulsing in case the over current protection (OCP) is triggered.

Heat sinks have been placed on the MOSFETs and their drivers to help them cool down when the pulse PSU is switching at high frequencies.

The layout of the power board has been optimized to reduce the overall current path across the PSU and a symmetrical configuration has been adopted to place the power switches (Figure 8). The placement of the MOSFET reduces the inductance of the board and therefore reduces the amount of electromagnetic interference EMI generated [33].

\subsection{THE CURRENT SENSING CIRCUITRY}

The current flowing through the inter-electrode gap is measured via a differential amplifier measuring the voltage across a current sensing resistor. It is important to have the current sensing resistor in series with the high side of the $\mathrm{H}$ bridge because it makes the OCP compatible with all types of pulse shape: at this point the current flows always in the same direction independently from the pulse polarity. According to Ohm's law, the voltage across this resistor is an image of the current flowing through the system.

The output of the differential amplifier (Figure 9) goes to two different parts:

- The peak detector

The peak detector plays a very important role as it delivers the peak value of the current to the motion controller. 


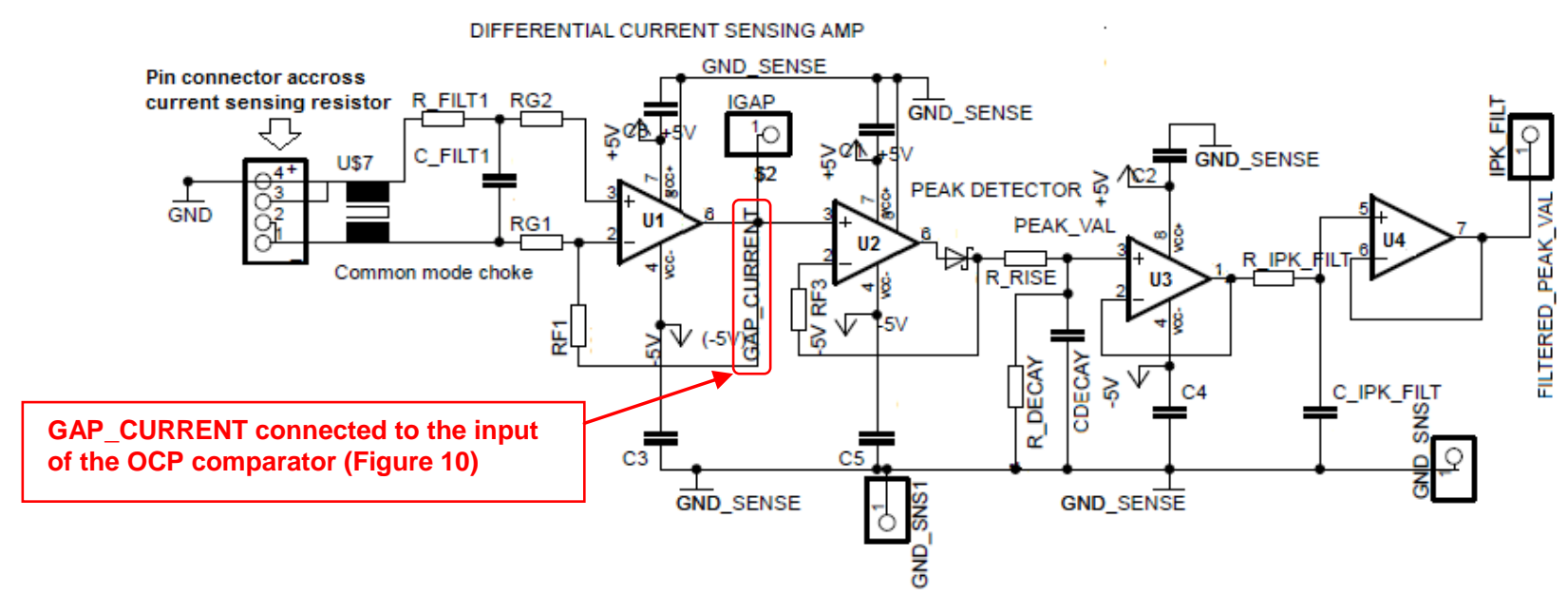

Figure 9. Schematic diagram of the current sensing and peak detector circuitry of the PSU prototype

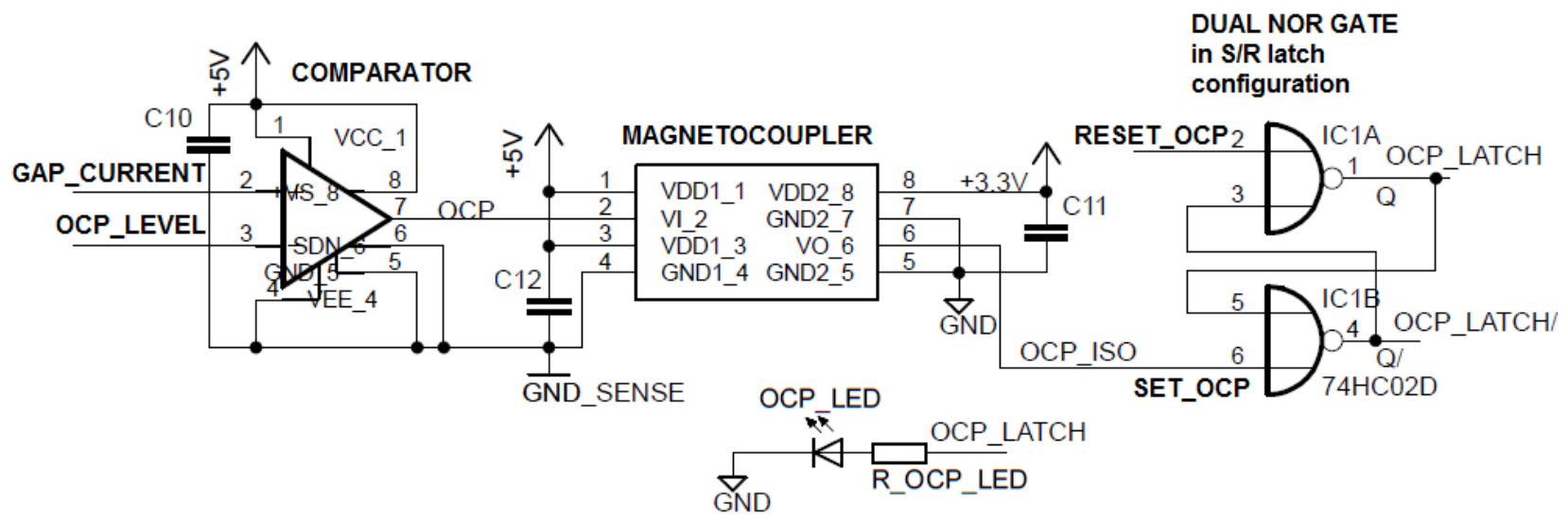

Figure 10. Schematic diagram of the OCP circuitry of the PSU prototype

The peak current value is used to control the IEG and is used as an input variable by the control algorithm. This peak detector uses a diode, which charges the capacitor CDECAY through the resistor R_RISE. The capacitor then discharges itself at a rate set by the resistor R_DECAY (Figure 9).

\section{- Overcurrent protection $(\mathrm{OCP})$ :}

The OCP (Figure 10) is made of an ultrafast comparator (LT1719) which will compare the output of the differential amplifier with the OCP level set by the microcontroller. If the measured current is higher than the present level, the output of the comparator will go HIGH and go through a magnetocoupler (which ensures the isolation between the OCP circuitry and the control circuitry) and will then set the $S / R$ latch gate to HIGH as well. The S/R latch - made of 2 NOR gates - will remain in that state until it is reset by the microcontroller. The OCP_LATCH/ signal will be set to LOW when a short circuit occurs. This will stop the pulses because it is connected to the $\overline{\mathrm{OCP}}$ pins of the AND gates seen in the control circuitry (Figure 6).

\section{RESUlTS}

\subsection{PSU TESTING}

The presented results have been obtained by connecting the output of the PSU to a $10 \mathrm{Ohm} 50 \mathrm{~W}$ resistor used as a test load which allows high current (up to 7A for 7VDC) to flow through the PSU (Figure 11). Commands are then sent to the PSU via the developed HMI and the obtained pulse shapes are visualized with a Wavepro 7300A Lecroy oscilloscope. The current flowing though the resistor is measured using a wideband terminated current transformer with a rise time of $7 \mathrm{~ns}$ and a bandwidth of $60 \mathrm{MHz}$ model $13 \mathrm{G} 1000$ from Lilco ltd.

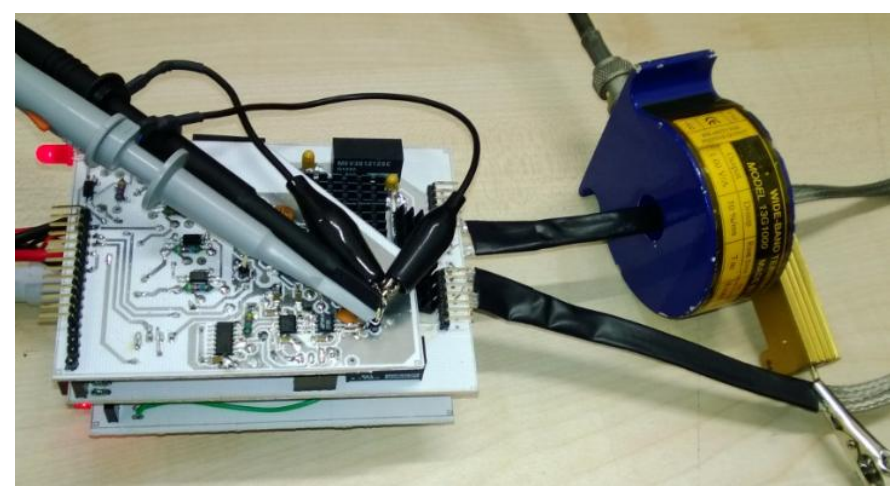

Figure 11. Picture of the PSU being tested with the $1 \mathrm{Ohm}$ load and current transformer

It was observed that when applying $6 \mathrm{~V}$ pulses to the $1 \mathrm{Ohm}$ load at a frequency of $2.5 \mathrm{MHz}$ and a duty cycle of $20 \%$, the impedance of the cables becomes so important that only half of the power is transmitted to the load. This highlights how essential a low inductance cabling is for the $\mu \mathrm{ECM}$ 
technology. The electrical specifications of the pulse PSU can be found in Table 1.

\begin{tabular}{|l|l|}
\hline Current Max & $10 \mathrm{~A}$ \\
\hline Frequency range & $2 \mathrm{kHz}-8 \mathrm{MHz}$ \\
\hline Voltage max & $15 \mathrm{~V}$ \\
\hline Smallest pulse duration & $50 \mathrm{~ns}$ \\
\hline
\end{tabular}

Table 1. Specs of the developed pulse PSU

\section{- On-board signals}

Different on-board signals can be observed while the PSU is pulsing (Figure 12). The OCP level and measured current signals are constantly compared and as soon as the measured current goes above the OCP level, the pulses are shut down. The peak value of the current is sent to a motion controller which controls the IEG and proceeds to the tool retraction when a short circuit is detected.

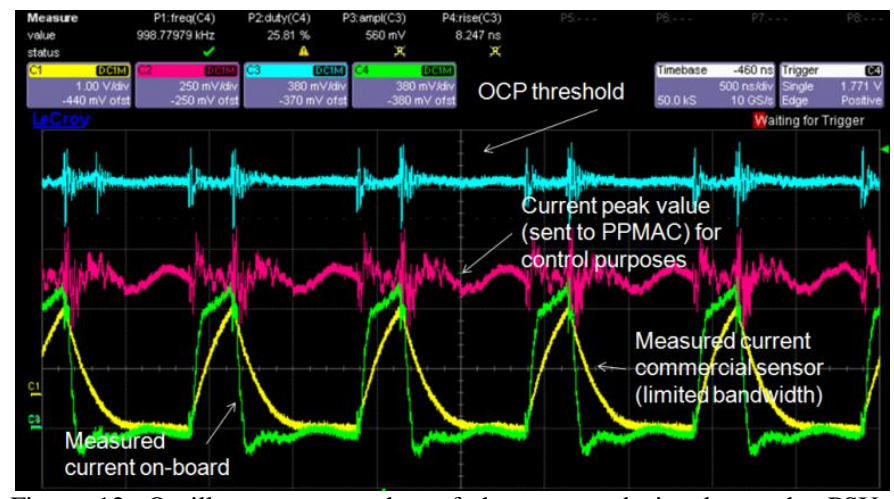

Figure 12. Oscilloscope screenshot of the measured signals on the PSU, $1 \mathrm{MHz}$ frequency, duty cycle of $25 \%$, pulse amplitude of $3.2 \mathrm{~V}$ and no offset during off-time $500 \mathrm{~ns} / \mathrm{div}$.

\begin{tabular}{|l|l|l|}
\hline Channel & Description & Scaling \\
\hline C1 & $\begin{array}{l}\text { Measured gap current via commercial } \\
\text { current sensor }\end{array}$ & $\begin{array}{l}1 \mathrm{~V} / \mathrm{div} ., \\
1 \mathrm{~V} / \mathrm{A}\end{array}$ \\
\hline C2 & Peak current value & $\begin{array}{l}250 \mathrm{mV} / \mathrm{div} ., \\
250 \mathrm{mV} / \mathrm{A}\end{array}$ \\
\hline C3 & OCP threshold level & $\begin{array}{l}380 \mathrm{mV} / \mathrm{div} . \\
380 \mathrm{mV} / \mathrm{A}\end{array}$ \\
\hline C4 & $\begin{array}{l}\text { Measured gap current via on-board current } \\
\text { sensing circuitry }\end{array}$ & $380 \mathrm{mV} / \mathrm{div} .$, \\
& $380 \mathrm{mV} / \mathrm{A}$ \\
\hline
\end{tabular}

Table 2. Description of the signals measured in Figure 12.

- OCP triggering trials

An important feature of the developed PSU is the time it takes for the pulses to be stopped after the over current protection (OCP) has been triggered. This represents the time during which the tool is exposed to an electrical and mechanical stress. The presented results are obtained by short-circuiting the output of the pulse PSU and sending pulses $(1 \mathrm{MHz}$, $25 \%$ duty cycle, $2 \mathrm{~V}$ pulse, $0 \mathrm{~V}$ offset). The OCP signal triggered at the first pulse and the pulses were stopped (Figure 13).

It can be seen from Figure 13 that the delay between the OCP being triggered and the pulses being stopped is less than 50ns.
The pulse duration is also reduced: instead of a 250ns pulse, a short pulse of $150 \mathrm{~ns}$ is generated.

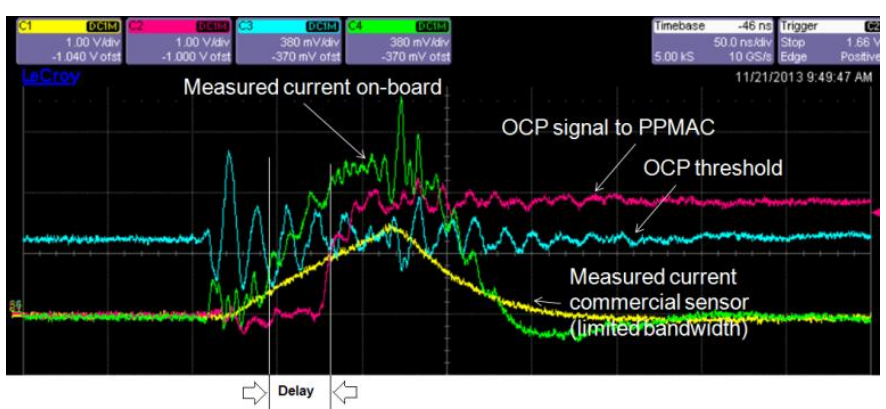

Figure 13: Oscilloscope screenshot of the OCP signal delay 50ns/div. (C1: Measured gap current via commercial current sensor at $1 \mathrm{~V} /$ div. and $1 \mathrm{~V} / \mathrm{A} ; \mathrm{C} 2$ : OCP signal 1V/div; C3: OCP threshold level at $380 \mathrm{mV} / \mathrm{div}$. and $380 \mathrm{mV} / \mathrm{A}$; C4: Measured gap current via on-board current sensing circuitry at $380 \mathrm{mV} / \mathrm{A}$ and $380 \mathrm{mV} /$ div.)

\subsection{PSU INSTALLATION AND MACHINING EXPERIMENTS}

The PSU has been installed on a self-developed $\mu \mathrm{ECM}$ machine (Figure 14). A significant effort has been taken to make the cables as short as possible:

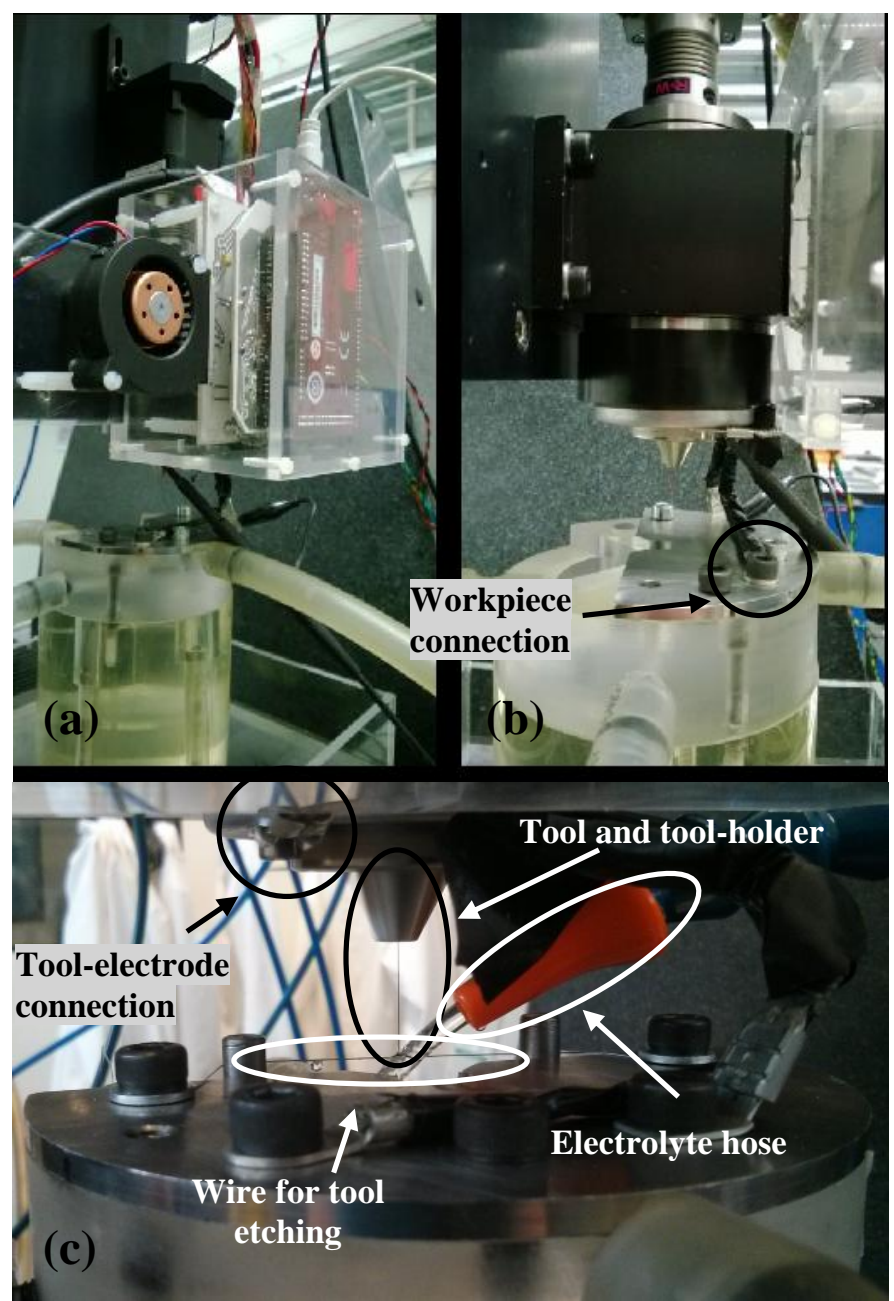

Figure 14. Pictures of the PSU mounted on the micro-ecm machine.

- The PSU is directly mounted on the $\mathrm{Z}$ axis very close to the tool-electrode; 
- When the electrode mounted on the $\mathrm{Z}$ axis is close to the workpiece, a second shorter cable is connected to the machining cell in order to further reduce the length of the current path during machining (Figure 14 (c)).

In the following experiments, a mixture of $0.1 \mathrm{M} \mathrm{H}_{2} \mathrm{SO}_{4}$ and $0.5 \mathrm{M} \mathrm{NaNO}_{3}$ solutions was used as electrolyte.

The positions of the surfaces of the wire and workpiece were determined by electrical contact via the OCP circuitry of the PSU. The OCP was set to trigger at a very low threshold for this operation.

\subsubsection{TOOL FABRICATION FOLLOWED BY WORKPIECE DRILLING}

The workpiece was one disk made of $18 \mathrm{NiCr} 6$ alloy which was provided by the automotive company Delphi UK. The disk is $1.1 \mathrm{~mm}$ thick.

The electrode in the tool-holder had a diameter of $170 \mu \mathrm{m}$ and was made of WC-Co alloy ( WC $+5 \% \mathrm{Co}$ ).

The micro tool was first etched to a diameter of $105 \mu \mathrm{m}$ via electrochemical turning (Figure 16). The electrode was brought very close to the wire with a gap of $10 \mu \mathrm{m}$ and electrolyte was supplied to the system via a nozzle (Figure 14 (c)). The shaft was spinning at 600rpm during the etching process and was slowly fed down towards the wire while ultrashort pulses were delivered to the IEG. This process used the following parameters: $-7 \mathrm{~V}$ pulses with no offset (pulse shape $\mathrm{n}^{\circ} 5$ on Figure 7), at a pulse period of $500 \mathrm{~ns}$ and a $50 \mathrm{~ns}$ pulse duration. Overcurrent protection was set to 0.7A. The wire had a diameter of $200 \mu \mathrm{m}$ and was made of steel. It was produced by Agie/Charmilles.
After the tool was fabricated, a $1.1 \mathrm{~mm}$ deep hole was drilled in the workpiece (Figure 17 \& Figure 18) with 8V pulses, a pulse period of $1 \mu$ s and 250ns pulse duration (Figure 15). A black film can be observed on the workpiece because of the carbide compounds created during the machining of the $18 \mathrm{NiCr} 6$ alloys. This phenomenon is well-known and was reported by Haisch et al. [34].

From the graphs in Figure 18 it can be seen that the tool progression was linear, with a lot of OCP retractions during the first half of the machining session. The machining time was 3748s. The sidewalls of the tool are not insulated so it can be observed that the current increases when drilling at a bigger depth.

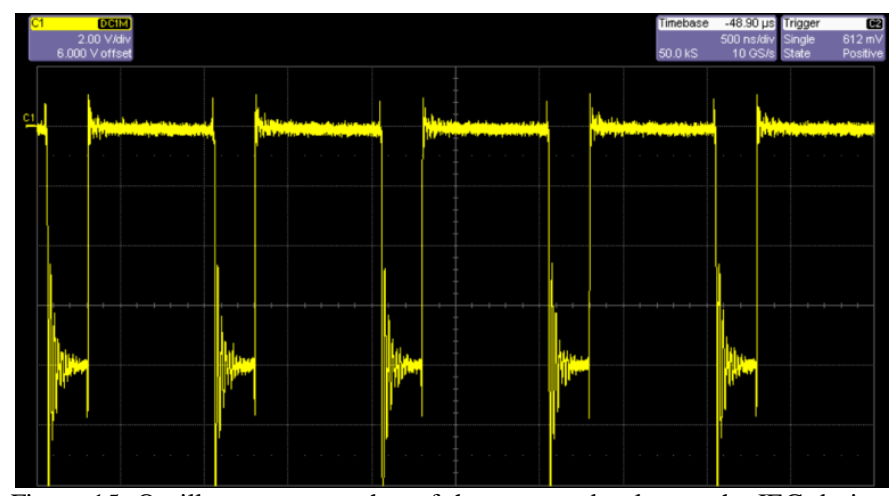

Figure 15. Oscilloscope screenshot of the measured pulses at the IEG during machining, $1 \mathrm{MHz}$ frequency, duty cycle of $25 \%$, pulse amplitude of $8 \mathrm{~V}$ and no offset during off-time 500ns/div.

The following pictures and diameter measurements have been taken with a Tesa-Visio 200GL.
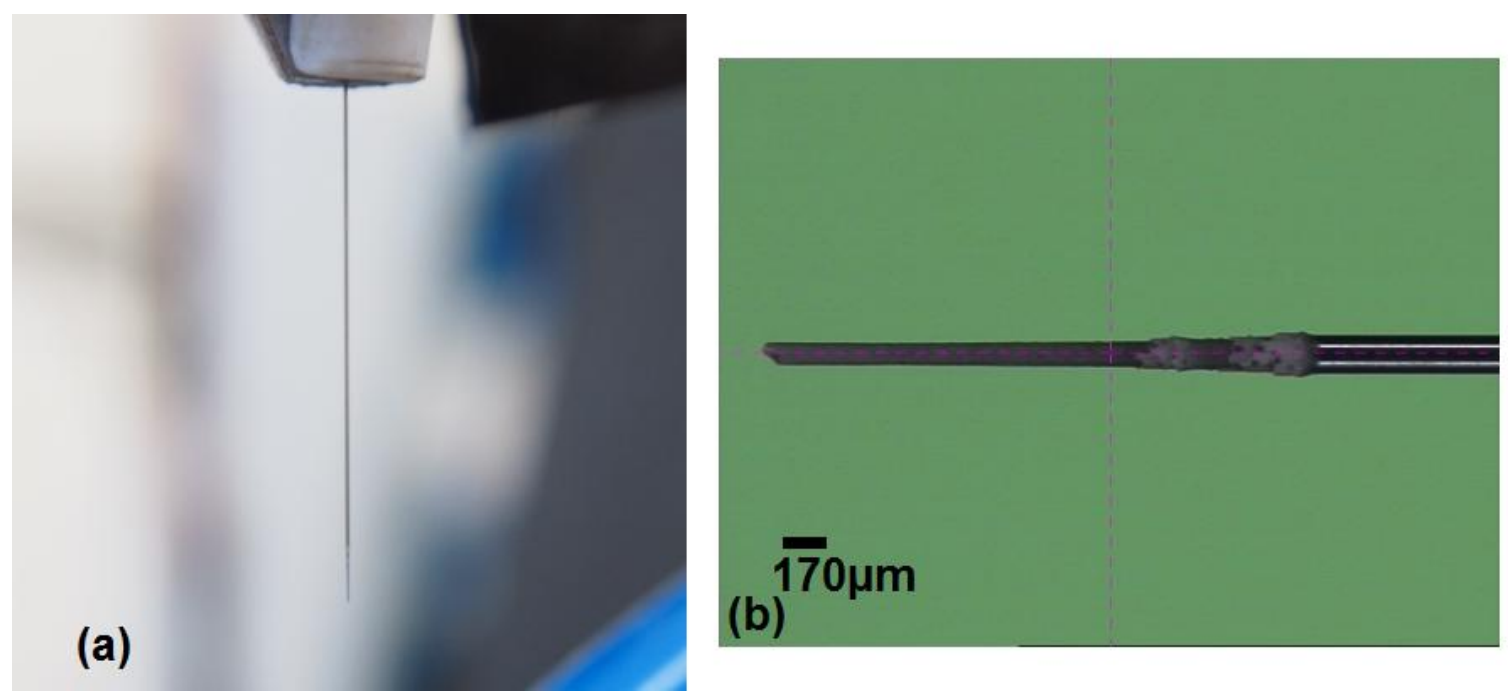

Figure 16. (a) Tool in the tool holder (b) Picture of the micro tip etched via Wire $\mu \mathrm{ECM}$ (electrochemical turning), a $\mathrm{NaNO}_{3}$ salt layer can be observed along the tool surface (WC-Co alloy, electrolyte $0.5 \mathrm{M} \mathrm{NaNO}_{3}+0.1 \mathrm{M} \mathrm{H}_{2} \mathrm{SO}_{4}$, pulse amplitude: $-7.5 \mathrm{~V}$, pulse duration: $50 \mathrm{~ns}$, pulse period: $500 \mathrm{~ns}$, feedrate: $0.3 \mu \mathrm{m} / \mathrm{s}$, diameter: $95 \mu \mathrm{m}$ ). 

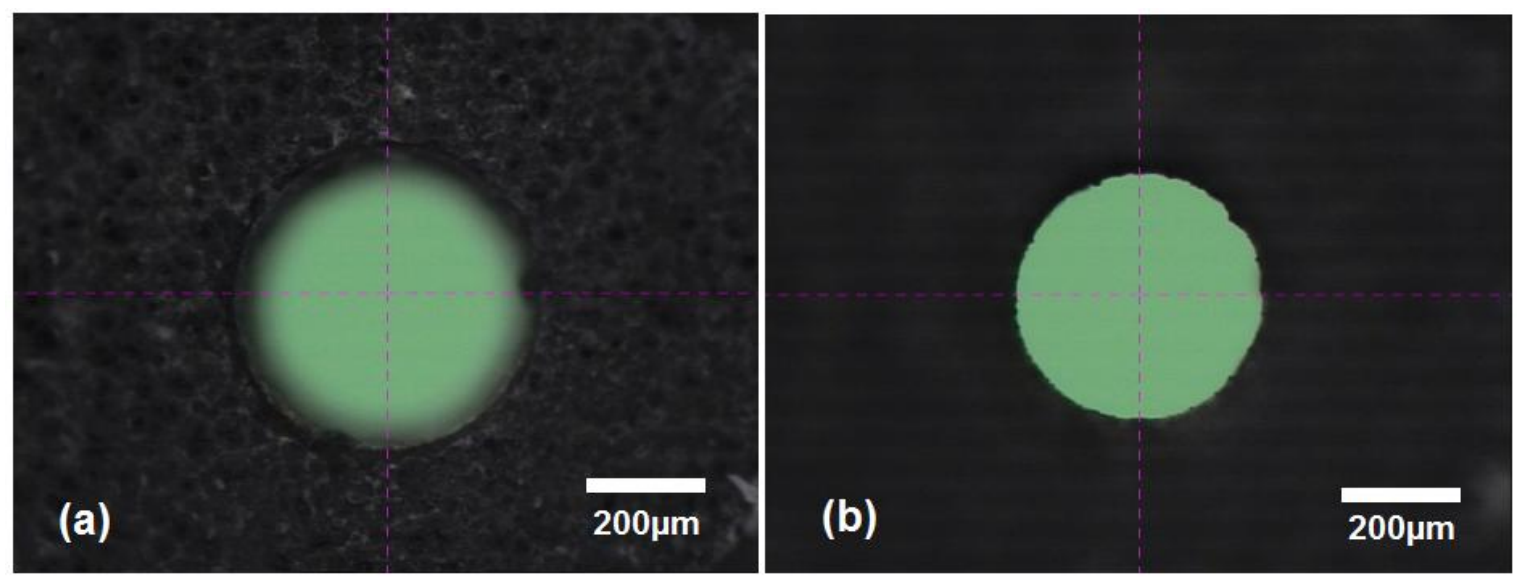

Figure 17. Picture of the hole fabricated by ECM with the WC-Co etched tool. (a) hole entrance, (b) hole exit (18NiCr6 alloy, depth: $1.1 \mathrm{~mm}$, hole entrance diameter: $517 \mu \mathrm{m}$, hole exit diameter: $414 \mu \mathrm{m}$, electrolyte $0.5 \mathrm{M} \mathrm{NaNO}_{3}+0.1 \mathrm{M} \mathrm{H}_{2} \mathrm{SO}_{4}$, pulse amplitude: $8 \mathrm{~V}$, pulse duration: $250 \mathrm{~ns}$, pulse period: $1 \mu \mathrm{s}$, feedrate: $0.3 \mu \mathrm{m} / \mathrm{s})$.

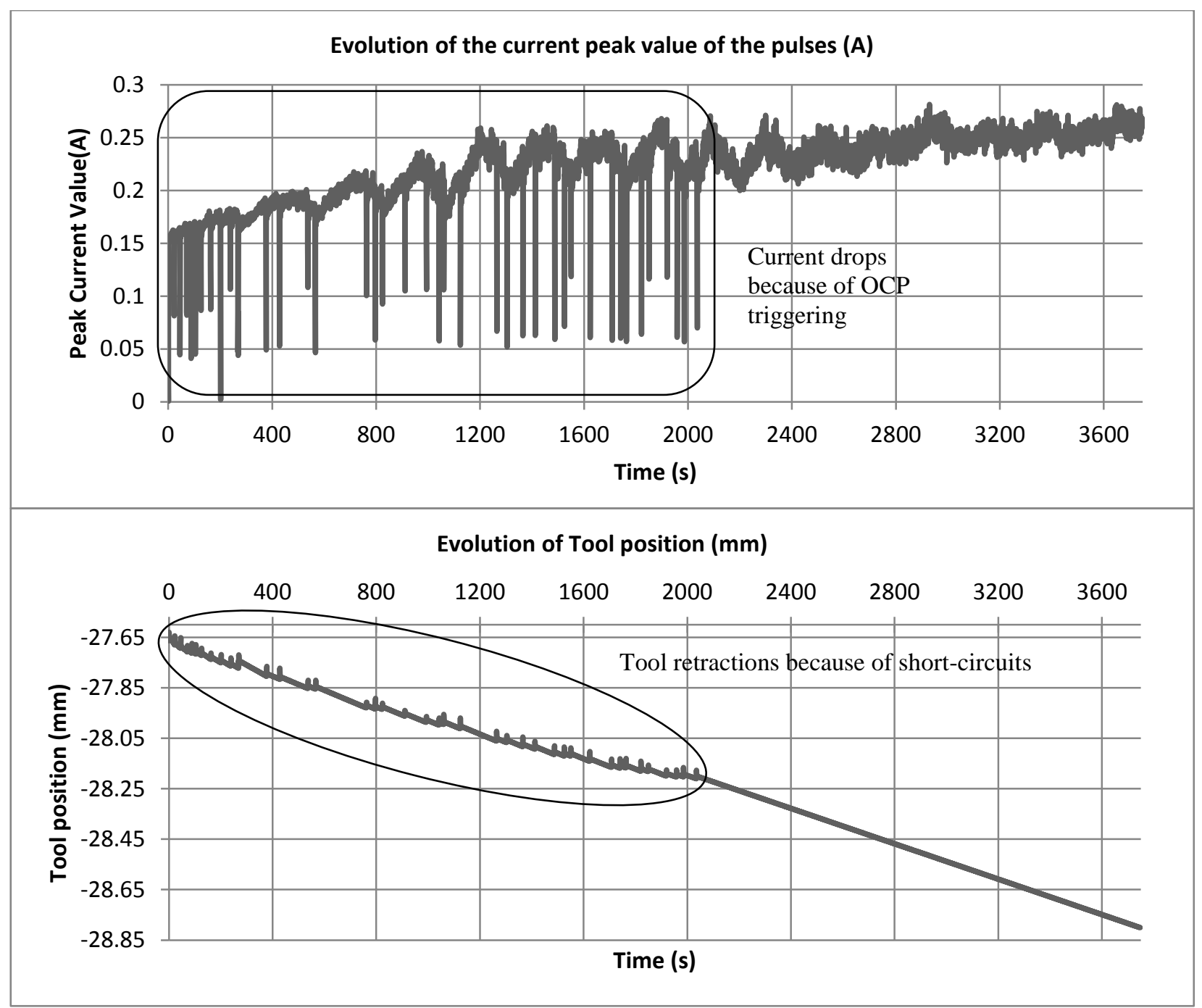

Figure 18. Graphs representing (a) the evolution of the current peak value of the pulses (in A) and (b) the evolution of the tool position (in mm) over time (in s) during the drilling process of the $18 \mathrm{NiCr} 6$ workpiece.

\subsubsection{MicRO-TOOL FABRICATIONS}

The pulse PSU was also used to machine micro tools out of WC-Co electrodes $(170 \mu \mathrm{m}$ diameter $)$ via electrochemical turning using the previously mentioned $200 \mu \mathrm{m}$ diameter wire.
A very sharp tool (Figure 19) was fabricated by repetitively scanning the surface of the wire at a fixed gap. The tip of the tool measures $5 \mu \mathrm{m}$. The machining of this tool was faster than the hole-drilling process and took only 350 seconds. 

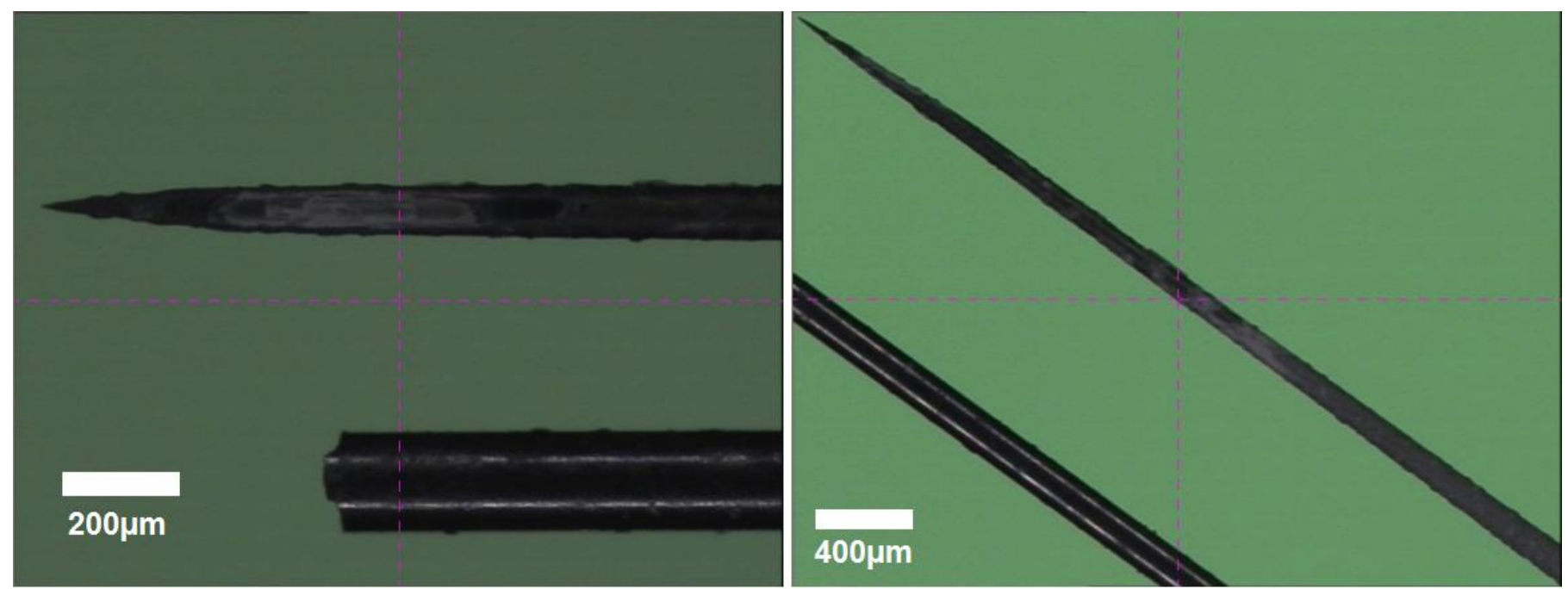

Figure 19. Tool of the shape of a needle made by micro electrochemical turning. A non-machined tool-electrode of $170 \mu \mathrm{m}$ is placed next to it for size comparison. (WC-Co alloy, electrolyte $0.5 \mathrm{M} \mathrm{NaNO}_{3}+0.1 \mathrm{M} \mathrm{H}_{2} \mathrm{SO}_{4}$, pulse amplitude: $-7.5 \mathrm{~V}$, pulse duration: $50 \mathrm{~ns}$, pulse period: $500 \mathrm{~ns}$, feedrate: $0.3 \mu \mathrm{m} / \mathrm{s}$, tip diameter: $5 \mu \mathrm{m}$ )
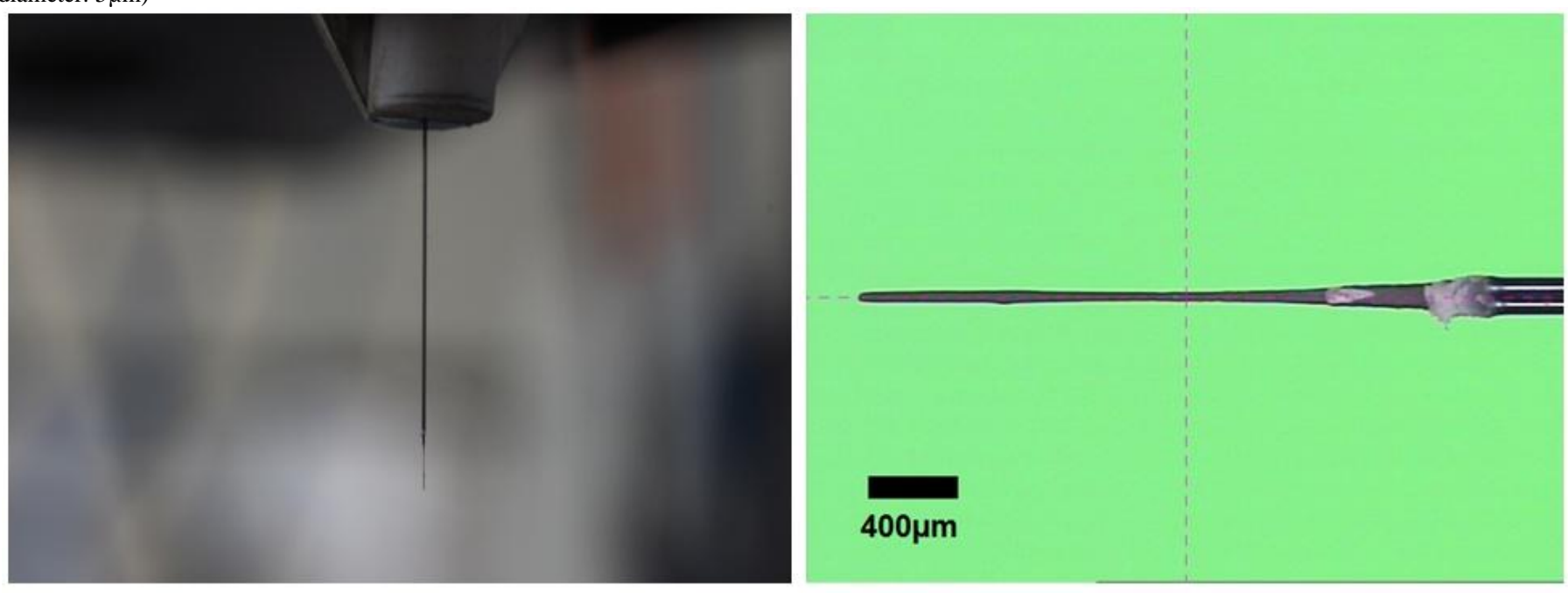

Figure 20. Micro-tool made by micro electrochemical turning. (WC-Co alloy, electrolyte $0.5 \mathrm{M} \mathrm{NaNO}_{3}+0.1 \mathrm{M} \mathrm{H}_{2} \mathrm{SO}_{4}$, pulse amplitude: $-7.5 \mathrm{~V}$, pulse duration: 50 $\mathrm{ns}$, pulse period: $500 \mathrm{~ns}$, feedrate: $0.2 \mu \mathrm{m} / \mathrm{s}$, diameter of tip: $57 \mu \mathrm{m}$, smallest diameter measured: $46 \mu \mathrm{m}$ )

Another technique was applied to produce the tool seen in Figure 20: the side gap between the micro tool and the wire was varied during the machining process to achieve this curved tool shape. The smallest diameter measured on that micro tool is $46 \mu \mathrm{m}$ and its tip is slightly bigger $(57 \mu \mathrm{m})$. The aim of this experiment was to fabricate a tool looking like the micro-probes used in coordinate-measuring machines (CMM).

\section{DISCUSSION AND CONCLUSIONS:}

The design of a power supply capable of delivering ultra short pulses and providing enough power to the IEG is essential in order to progress in the development of $\mu \mathrm{ECM}$ equipment. In this paper, a review for the pulse PSU requirements in $\mu \mathrm{ECM}$ has been done and a device meeting those requirements has been developed and tested. An overcurrent protection (OCP) system has been designed to protect the tool against undesired events occurring within the interelectrode gap during machining.

A quick communication protocol between the power supply and the motion controller is essential for the successful control of the $\mu \mathrm{ECM}$ process. Therefore, the developed pulse PSU provides the control system with signals such as the current peak value as well as the OCP signal, in order to quickly react and adapt the motion of the tool.

The developed pulse PSU was used to produce micro tools of different tip diameters $(95 \mu \mathrm{m}, 57 \mu \mathrm{m}$ and $5 \mu \mathrm{m})$ and drill a deep hole $(1.1 \mathrm{~mm})$ in $18 \mathrm{NiCr} 6$ with an on-line fabricated tool. The diameter $(414 \mu \mathrm{m})$ of the drilled hole was relatively greater than the tool diameter. This result is mainly linked to 2 parameters: 1) the tool run-out was quite significant 2) the machining time was very long so a bigger volume was machined.

Further work will be done to reduce the diameter of the drilled holes by improving the tool clamping system to reduce the tool run-out.

\section{ACKNOWLEDGMENT}

The research reported in this paper is supported by the European Commission within the project "Minimizing Defects 
in Micro-Manufacturing Applications (MIDEMMA)" (FP72011-NMP-ICT-FoF-285614)

\section{REFERENCES}

1. McGeough JA (1974) Principles of Electrochemical Machining. Chapman and Hall, London

2. Kozak J, Rajurkar KP, Makkar Y (2004) Study of Pulse Electrochemical Micromachining. J Manuf Process 6:7-14. doi: 10.1016/S1526-6125(04)70055-9

3. Kozak J, Rajurkar KP, Makkar Y (2004) Selected problems of micro-electrochemical machining. J Mater Process Technol 149:426-431. doi: 10.1016/j.jmatprotec.2004.02.031

4. Zhang Z, Zhu D, Qu N, Wang M (2007) Theoretical and experimental investigation on electrochemical micromachining. Microsyst Technol 13:607-612. doi: 10.1007/s00542-006-0369-7

5. Kamaraj AB, Sundaram MM (2013) Mathematical modeling and verification of pulse electrochemical micromachining of microtools. Int J Adv Manuf Technol. doi: 10.1007/s00170013-4896-y

6. Kock M, Kirchner V, Schuster R (2003) Electrochemical micromachining with ultrashort voltage pulses-a versatile method with lithographical precision. Electrochim Acta 48:3213-3219. doi: 10.1016/S0013-4686(03)00374-8

7. Cagnon L, Kirchner V, Kock M, et al. (2003) Electrochemical Micromachining of Stainless Steel by Ultrashort Voltage Pulses. Zeitschrift für Phys Chemie 217:299-314. doi: 10.1524/zpch.217.4.299.20383

8. Schuster R, Kirchner V, Allongue P, Ertl G (2000) Electrochemical Micromachining. Science (80- ) 289:98-101. doi: $10.1126 /$ science. 289.5476 .98

9. Schulze H, Borkenhagen D, Burkert S (2008) Demands on process and process energy sources for the electro-erosive and electrochemical micro machining. J Mater 1:1383 - 1386. doi: $10.1007 / \mathrm{s} 12289-008-0$

10. Zhang Z, Wang Y, Chen F, Mao W (2011) A Micro-machining system based on electrochemical dissolution of material. Russ J Electrochem 47:819-824. doi: 10.1134/S1023193511070172

11. Lee ES, Baek SY, Cho CR (2007) A study of the characteristics for electrochemical micromachining with ultrashort voltage pulses. Int J Adv Manuf Technol 31:762-769. doi: 10.1007/s00170-005-0247-y

12. Mathew R, Sundaram MM (2012) Modeling and fabrication of micro tools by pulsed electrochemical machining. J Mater Process Technol 212:1567-1572. doi: 10.1016/j.jmatprotec.2012.03.004

13. Liu Y, Zhu D, Zhu L (2012) Micro electrochemical milling of complex structures by using in situ fabricated cylindrical electrode. Int J Adv Manuf Technol 60:977-984. doi: 10.1007/s00170-011-3682-y

14. Choi SH, Ryu SH, Choi DK, Chu CN (2007) Fabrication of WC micro-shaft by using electrochemical etching. Int J Adv Manuf Technol 31:682-687. doi: 10.1007/s00170-005-0241-4

15. Yang I, Park MS, Chu CN (2009) Micro ECM with ultrasonic vibrations using a semi-cylindrical tool. Int J Precis Eng Manuf 10:5-10. doi: 10.1007/s12541-009-0020-5

16. Huang SH, Huang FY, Yan BH (2004) Fracture strength analysis of micro WC-shaft manufactured by micro-electro-discharge machining. Int J Adv Manuf Technol 26:68-77. doi: 10.1007/s00170-003-1974-6

17. Burkert S, Schulze H, Gmelin T, Leone M (2009) THE PULSE ELECTROCHEMICAL MICROMACHINING ( PECMM ) SPECIFICATIONS OF THE PULSE UNITS -. Int J Mater Form 2:645-648. doi: 10.1007/s12289-009-0464-2

18. Fan Z-W, Hourng L-W, Lin M-Y (2012) Experimental investigation on the influence of electrochemical microdrilling by short pulsed voltage. Int J Adv Manuf Technol 61:957-966. doi: 10.1007/s00170-011-3778-4

19. Park BJ, Kim BH, Chu CN (2006) The Effects of Tool Electrode Size on Characteristics of Micro Electrochemical Machining. CIRP Ann - Manuf Technol 55:197-200. doi: 10.1016/S00078506(07)60397-7

20. Zhang YJ, Tang YJ, Liu XK, et al. (2009) Development of UltraShort Pulse Power Supply Applicable to Micro-ECM. Mater Sci Forum 626-627:369-374. doi: 10.4028/www.scientific.net/MSF.626-627.369

21. Muetze A, Oh HW (2008) Design Aspects of Conductive Microfiber Rings for Shaft-Grounding Purposes. IEEE Trans Ind Appl 44:1749-1757. doi: 10.1109/TIA.2008.2006421

22. Bhattacharyya B, Munda J (2003) Experimental investigation on the influence of electrochemical machining parameters on machining rate and accuracy in micromachining domain. Int $\mathbf{J}$ Mach Tools Manuf 43:1301-1310. doi: 10.1016/S08906955(03)00161-5

23. Oh KS (2000) MOSFET Basics, Application Note AN9010,. Fairchild Semicond 1-37.

24. Balogh L (2001) Design And Application Guide For High Speed MOSFET Gate Drive Circuits. Proc. Power Supply Des. Semin. (SEM 1400)

25. Tang T, Burkhart C (2009) Hybrid MOSFET/driver for ultra-fast switching. IEEE Trans Dielectr Electr Insul 16:967-970. doi: 10.1109/TDEI.2009.5211841

26. Campbell D, Harper J, Natham, Vinodhkumar, Xiao F, Sundararajan R (2008) A Compact High Voltage Nanosecond Pulse Generator. Proc. ESA Annu. Meet. Electrost. 2008. pp $1-12$ 
27. Röblitz M (2007) Integrierte Pulsquelle für die gepulste Elektrochemische bearbeitung von Mikrostructuren. Otto-vonGuericke Universität Magdeburg

28. Yong L, Yunfei Z, Guang Y, Liangqiang P (2003) Localized electrochemical micromachining with gap control. Sensors Actuators A Phys 108:144-148. doi: 10.1016/S09244247(03)00371-6

29. Schuster R, Kirchner V (2004) Method for electrochemically processing material. US $6689269 \mathrm{~B} 1$

30. Ozkeskin FM (2008) Feedback controlled high frequency electrochemical micromachining. Texas A\&M University

31. Mithu MAH, Fantoni G, Ciampi J, Santochi M (2012) On how tool geometry, applied frequency and machining parameters influence electrochemical microdrilling. CIRP J Manuf Sci Technol 5:202-213. doi: 10.1016/j.cirpj.2012.07.006

32. Mithu M a. H, Fantoni G, Ciampi J (2011) The effect of high frequency and duty cycle in electrochemical microdrilling. Int J Adv Manuf Technol 55:921-933. doi: 10.1007/s00170-0103123-3

33. Jauregui D (2009) Reducing Ringing Through PCB Layout Techniques. 1-6.

34. Haisch T, Mittemeijer EJ, Schultze JW, Gmbh RB (2004) High rate anodic dissolution of $100 \mathrm{Cr} 6$ steel in aqueous $\mathrm{NaNO} 3$ solution. 997-1005. 